\title{
Vocal process granuloma - a case report
}

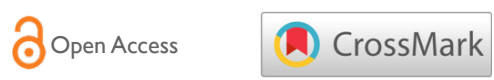

Volume 10 Issue I - 2018

Keywords: vocal process granuloma, extraoesophageal reflux, chronic inflammation, capillary proliferation, fibrosis

\section{Introduction}

Vocal process granuloma is a benign inflammatory lesion formed by granulation tissue that occurs primarily in medial surface of the vocal process of arytenoid cartilage. ${ }^{1}$

They are thought to arise due to repeated injury to the mucoperichondrium over the vocal processes from mechanical trauma, either following laryngeal intubation or repeated high velocity impact of the vocal processes against each other from throat clearing, coughing or talking in a habitually low pitched or hyperfunctional manner. ${ }^{2,3}$

In addition to above factors, extraoesophageal reflux has been found to be a contribute to factor that add to symptoms leading to the mechanical trauma and also prevents healing of the injured mucosa. ${ }^{4,5}$ The most common symptom is hoarseness combined with persistent throat clearing, sore throat, and globus sensation. Despite its infrequent occurrence, contact granuloma has received considerable attention in the literature because of frustration encountered in its clinical management. The healing time is long, regardless of treatment, and the recurrence rate after surgery is greater than $90 \%{ }^{6}$

\section{Case report}

A 35yrs old male patient presented to our ENT OPD with a complaint of progressive hoarseness with gradual voice loss over the 3 months. He had symptoms of extra oesophagel reflux and had history of PND and sneezing. On direct laryngoscopic examination with 70degree endoscopy, a granulomatous fleshy growth was observed from medial surface of the right vocal process of arytenoids cartilage. The vocal fold mobility was restricted due to mass effect but there was no stridor or any sign of respiratory distress.

Patient was started on antireflux, antiallegic and steroid nasal sprays for 15 days, along with speech therapy by speech and language pathologist.

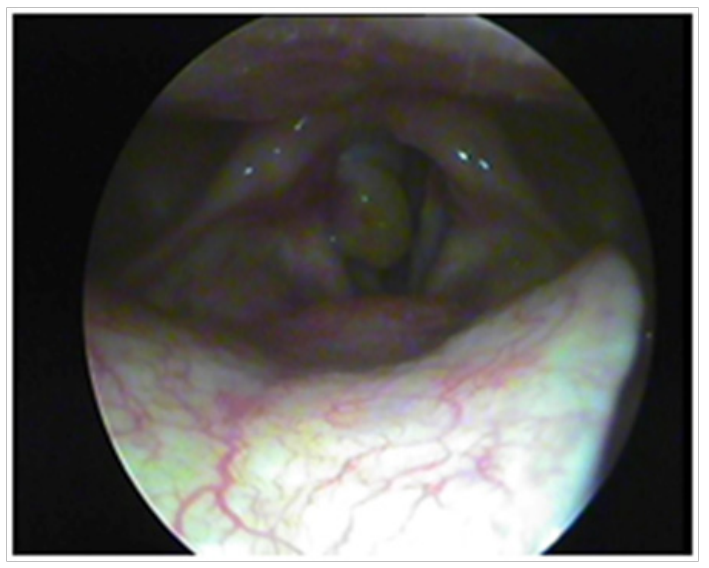

Nitin Arora,' Jyoti Singh, ${ }^{2}$ Jai Lal Davessar ${ }^{3}$

'Senior Resident, Baba Farid University of Health Sciences, ENT, GGS Medical College, India

${ }^{2}$ PG 3rd Year, ENT, GGS Medical College, India

${ }^{3} \mathrm{Head}$ of Department, ENT, GGS Medical College, India

Correspondence: Nitin Arora, Senior Resident, Baba Farid University of Health Sciences, Faridkot, Punjab, India, Tel +919815260243, Email drnitinarora89@gmail.com

Received: November 03, 2017 | Published: February 09, 2018

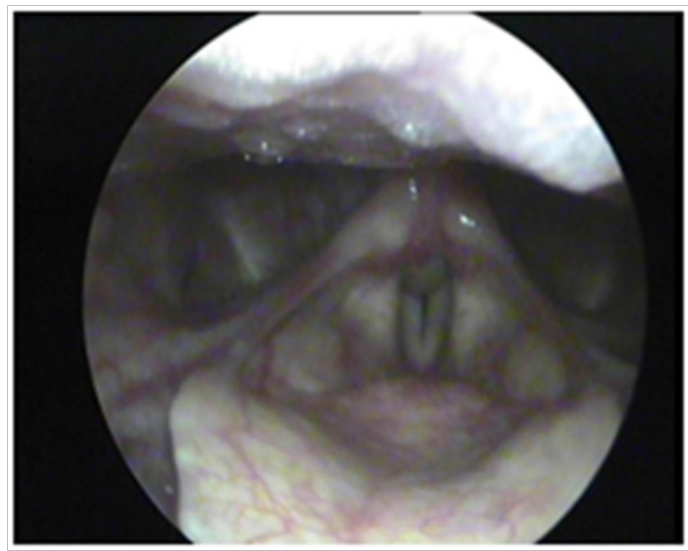

\section{Post Treatment Post Treatment}

Post treatment size of granuloma has shrunken significantly with improvement in the voice .Patient has been further instructed to continue treatment for one month more.

\section{Discussion}

Vocal process granuloma (VPG) is a troublesome problem for the patients, speech language pathologists, and the ENT doctors. Aetiologies include voice abuse, gastroesophageal reflux, and endotracheal intubation. Diagnosis of contact granuloma is simple to perform by means of clinical examination alone, because of its characteristic location and peculiar appearance. No other tests are necessary. Biopsy is performed if malignancy is suspected. Despite its name, contact granuloma is not a granuloma in the pathological sense. On light microscopy of the specimen, we may see some focal ulceration, epithelial hyperplasia, necrotic tissue, acute and/or chronic inflammation, capillary proliferation, fibrosis, and partially necrotic arytenoid cartilage. ${ }^{8}$ A grading system has been proposed on the basis of endoscopic appearance of the granuloma. Grade 1 lesion is limited to the vocal process, with no ulceration in a sessile lesion. Grade 2 lesion is limited to the vocal process and is a ulcerated or pedunculated lesion. Grade 3 lesion extends beyond the vocal process but does not cross the midline of the fully abducted vocal fold. Grade 4 lesion 
extends beyond the vocal process and crosses over the midline of the fully abducted vocal fold. Unilateral cases are designated as "A" and bilateral ones as "B". ${ }^{9}$ The granuloma in our case report had a grading of $4 \mathrm{~A}$.

The main treatment principles include reducing the effects of laryngeal irritants, i.e. stopping smoking, improving vocal hygiene, treating any respiratory tract infections, allergies and extraoesophageal reflux. $^{10}$

Other treatment options include intralesional injection of steroids (Triamcinolone) or Botulinum toxin, this can reduce inflammation and can reduce the impact of the vocal processes. ${ }^{11,12}$ Surgical treatment consists of microlaryngeal excision under direct laryngoscopy and is indicated for the lesion has reached the pedunculated stage and is causing respiratory obstruction, removal at the sessile stage is contraindicated due to the high incidence of recurrence. ${ }^{13}$

\section{Conclusion}

Vocal granuloma is a highly recurrent disease. High clinical suspicion and appropriate history is necessary for diagnosis. Treatment of the inciting and underlying cause is necessary. If the original inciting cause persists, it may recur locally.

\section{Acknowledgements}

None.

\section{Conflicts of interest}

Author declares there are no conflicts of interest.

\section{Funding}

None.

\section{References}

1. Shin $\mathrm{T}$, Watanabe $\mathrm{H}$, Oda $\mathrm{M}$, et al. Contact granulomas of the larynx. Eur Arch Otorhinolaryngol. 1994;251(2):67-71.
2. Hillman RE, Holmberg EB, Perkell JS, et al. Objective assessment of vocal hyperfunction: an experimental framework and initial results. $J$ Speech Hear Res. 1989;32(2):373-392.

3. Ylitalo R, Hammarberg B. Voice characteristics, effects of voice therapy, and long-term follow-up of contact granuloma patients. $J$ Voice. 2000;14(4):557-566.

4. Hoffman HT, Overholt EM, Karnell MP, et al. Granuloma contact ulcers and other posterior lesions. In: Ossoff RH, et al. (Eds.), The larynx. Philadelphia: Lippincott Williams 8: Wilkins, USA. 2003. p.203-23.

5. Ludemann JP, Manoukian J, Shaw K, et al. Effects of simulated gastroesophageal reflux on the untraumatized rabbit larynx. $J$ Otolaryngol. 1998;27(3):127-131.

6. Farwell DG, Belafsky PC, Rees CJ. An endoscopic grading system for vocal pro- cess granuloma. J Laryngol Otol. 2008;122(10):1092-1095.

7. Jackson C. Contact ulcer of the larynx. Ann Otol Rhinol Laryngol. 1928;90:48-52.

8. Devaney KO, Rinaldo A, Ferlito A. Vocal process granuloma of the larynx- recognition, differential diagnosis and treatment. Oral Oncol. 2005;41(7):666-669.

9. Farwell DG, Belafsky PC, Rees CJ. An endoscopic grading system for vocal pro- cess granuloma. J Laryngol Otol. 2008;122(10):1092-1095.

10. Wani MK, Woodson GE. Laryngeal contact granuloma. Laryngoscope. 1999;109(10):1589-1593.

11. Nasri S, Sercarz JA, McAlpin T, et al. Treatment of vocal fold granuloma using botulinum toxin A. Laryngo- scope. 1995;105(6):585-588.

12. Pham J, Yin S, Morgan M, et al. Botulinum toxin: helpful adjunct to early resolution of laryngeal granulomas. J Laryngol Otol . 2004;118(10):781-785.

13. Snow J, Harano M, Balogh K. Postintubation granuloma of the larynx. Anesth Analg. 1966;48:425-428. 